\title{
Vision of Strabismic Children in Ilorin, Nigeria
}

\author{
IR Azonobi MBBS, FMCOph; FO Olatunji MBBS, FMCOph, FICS; J Adido MBBS, FMCOph, \\ FICS; OO Osayande MBBS, FMCOph \\ Department of Ophthalmology, University of Ilorin Teaching Hospital, Ilorin, Kwara State, Nigeria
}

\section{AbSTRACT}

Objective: This study was conducted to evaluate the visual pattern of strabismic children.

Methods: A cross-sectional survey was carried out among primary school children in Ilorin South Local Government Area. A cluster random sampling technique was used to select the subjects for this study. The pattern of vision of children found to have ocular misalignment was studied.

Results: A total of 7288 school children were screened and this yielded 22 cases of esotropia and 10 cases of exotropia. Their ages ranged from 2 to 16 years; $78.1 \%$ of the study group had normal vision; $3.1 \%$ had low vision and another $3.1 \%$ was blind. Eight-two per cent (82\%) of the children with esotropia had normal vision, while $4.5 \%$ were blind; $70 \%$ of the children with exotropia had normal vision; $10 \%$ of exotropics had low vision. Twenty-five per cent $(25 \%)$ of the strabismic population was amblyopic, and the majority of the cases of amblyopia $(62.5 \%)$ were associated with esotropia. The prevalence of strabismic amblyopia was found to be $0.11 \%$.

Conclusion: The majority of strabismic children had normal vision. The prevalence of low vision and blindness was low. The prevalence of strabismic amblyopia was also low in the study population and most of it was associated with esotropia.

Key words: esotropia, exotropia, amblyopia, children, Nigeria

\section{INTRODUCTION}

Visual loss is the most serious consequence of strabismus ${ }^{1}$ and is usually due to amyblyopia. Strabismic deviation causes visual acuity depression of approximately $34 \%$ in the affected eye when compared with visual acuity levels in the normal eye. $^{2}$

Strabismus is the most common predisposing factor in the development of amblyopia, approximately $40 \%$ of children who manifest strabismus develop amblyopia. ${ }^{3}$ Severe amblyopia is a significant risk factor for blindness in the strabismic eye. ${ }^{2}$

Strabismic amblyopia is a sensory adaptation produced by a misalignment of the visual axis. It results from long continued fixation by the dominant eye and facultative suppression of the images of the deviating eye. ${ }^{4}$ This is due to competitive interaction between neurons carrying the non fusible inputs from the two eyes leading to a domination of the cortical vision centres by the fixating eye and a chronically reduced responsiveness to the input from the non fixating eye. ${ }^{5}$

Esodeviations are more commonly associated with amblyopia compared with exodeviations. This is probably because most childhood exotropias are intermittent. ${ }^{6}$

Strabismic amblyopia when detected early is reversible leading to an improvement of the vision of the child.

Information on the visual pattern of strabismic children is scanty. This study was therefore carried out to evaluate the visual pattern of strabismic children, especially as it relates to ambylopia.

\section{MATERIALS AND METHODS}

\section{Duration and Location}

The study took place at Ilorin South Local Government Area over a period of one year.

\section{Inclusion Criteria}

1. A primary school pupil of any of the selected schools

2. A school child with manifest strabismus in the above schools.

\section{Exclusion Criteria}

1. A primary school child not belonging to the selected schools.

2. Children with manifest strabismus whose squint is associated with a systemic or ocular pathology e.g., cataract, macular scar, central nervous system diseases e.g., cranial nerve palsies.

${ }^{*}$ Correspondence: Dr IR Azonobi, Department of Ophthalmology, University of Ilorin Teaching Hospital, Ilorin, Kwara State, Nigeria 


\section{Method of Patient Selection}

A cluster random sampling technique was used to select the subjects of this study. Each primary school in the local government area was randomly assigned a code ranging from 001 to 033 and a list was thus compiled of all the public schools. This list formed the sampling frame with each school representing a sampling unit (a cluster). In every cluster, all eligible members were examined to select the subjects of this study (strabismic patients). Samples (clusters) were selected for screening, using a simple random sampling technique from an already drawn sampling frame. Each time a cluster was selected for screening it was deleted from the sampling frame to prevent its further selection.

\section{Proforma}

A proforma was designed under two sections. In 'Section A', the child's general information namely identity, age, sex, school and class was collected. In 'Section B', information on full ocular examination of the child, namely, visual acuity (with and without pinhole), and with correction was recorded. In addition, information on the type of squint, extraocular motility assessment, anterior and posterior segment examination and information on the refractive state of the eye was collected.

\section{Consent/Ethical Clearance}

Consent was obtained from the education authority of Ilorin South Local Government Area and from the parents of the children before commencement of this study. Ethical clearance was also obtained from the ethics committee of the University of Ilorin Teaching Hospital.

\section{Procedure}

The children were screened for ocular misalignment using the Hirschberg method and the cover and uncover test. Examination proceeded from the most elementary class in the school and ended in the highest grade - primary six. Children that were found to have ocular misalignment were taken to the hospital at a later date after obtaining consent from their parents. A teacher was assigned by the school authority to accompany the children to the hospital (Ayo Bello Memorial Eye Centre).

Visual acuity was assessed with and without pinhole using the 'alphabet optotype' and ' $\mathrm{E}$ ' chart for children who had difficulty with the alphabet optotype. For very young children ( $<5$ years) visual acuity was assessed using the Kay's picture chart.

Extraocular motility assessment and anterior segment examination were then done using a bright pen torch. Funduscopy was done using a Keeler ophthalmoscope. A pilot survey had earlier been carried out on 14 eyes of 7 children selected randomly from the schools to compare cycloplegic refraction using one per cent ( $1 \%$ ) tropicamide and a non cycloplegic refraction using a topcon 8000 autorefractometer. The results showed that the difference between the two was not statistically significant. For this study, a non-cycloplegic refraction was done using a topcon 8000 autorefractometer followed by a subjective refraction. The pupils were then dilated with one per cent $(1 \%)$ tropicamide and a direct and indirect ophthalmoscopy was performed to rule out any organic pathology.

Children whose visual acuity in either or both eyes could not be improved with their best possible correction and those that improved, but could not be corrected to normal vision $(6 / 9)$, in the absence of any ocular abnormality to explain the depressed vision, were classified as amblyopic. This was confirmed by asking them to read the Snellen linear optotype acuity chart. An improvement by two or more lines confirmed amblyopia.

\section{Statistical Analysis}

All records were cross checked, entered and analyzed using Epi info version 6.04, SPSS 12.01 and a pocket size scientific calculator.

\section{RESULTS}

A total of 7288 school children (3766 boys, 3522 girls) were screened over a one-year period. Thirty-two cases of strabismus were diagnosed. There were 22 cases of esotropia and 10 cases of exotropia made up of (19 males and 13 females). Their ages ranged from 2-16 years, with a mean of 9.5 years $(\mathrm{SD} \pm 5.92)$. Seventy-eight per cent $(25)$ of the strabismic population had normal vision; $3.1 \%$ (one child) was blind. Also low vision was found in 3.1\% (table 1).

Table 1. Visual pattern of the strabismic population

\begin{tabular}{lcc}
\hline Visual acuity (Better eye) & Number & Percentage \\
\hline Normal vision $(6 / 6-6 / 18)$ & 25 & 78.1 \\
Low vision $(<6 / 18-3 / 60)$ & 1 & 3.1 \\
Blind $(<3 / 60)$ & 1 & 3.1 \\
Non-response & 5 & 15.6 \\
\hline Total & 32 & 100.0 \\
\hline
\end{tabular}

Eighteen $(82.0 \%)$ of the esotropic patients had visual acuity in the normal range in their better eye, while one (4.5\%) was blind (figure 1). Similarly, $7(70 \%)$ of the exotropic patients had normal vision while $1(10 \%)$ had low vision. Seventy-one per cent $(71 \%)$ had normal vision in the strabismic eye; while $22 \%$ and $7 \%$ had low vision and blindness respectively (figure 2). Eight (25\%) of the strabismic population were amblyopic (figure 3.) 


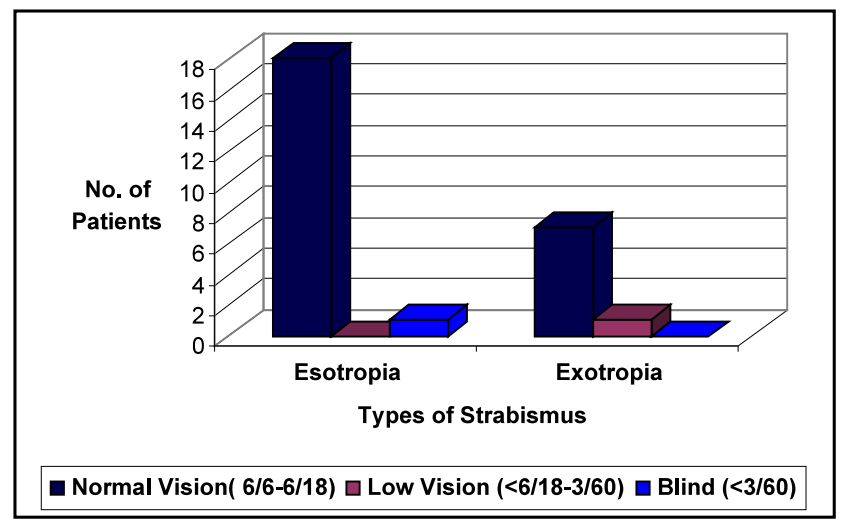

Figure 1. Visual pattern in relation to types of strabismus

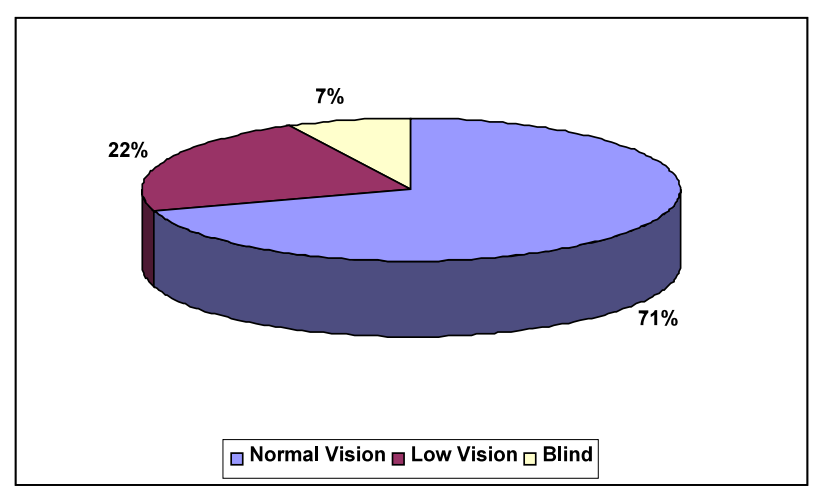

Figure 2. Vision in the strabismic eye

The majority of cases with amblyopia (62.5\%) were associated with esotropia while $37.5 \%$ were associated with exotropia (table 2). Strabismic amblyopia had a prevalence of $0.067 \%$ among cases of esotropia and $0.041 \%$ among cases of exotropia in the study population. The combined prevalence of strabismic amblyopia was $0.11 \%$.

\section{DISCUSSION}

In this study, $78.1 \%$ of the total study population had visual acuity in the normal range, while $3.1 \%$ had low vision and blindness. Also $81.8 \%$ and $70.0 \%$ of pupils with esotropia and exotropia had their visual acuity in the normal range. Low vision occurred in $10 \%$ of exotropic pupils, while blindness

Table 2. Amblyopia in relation to type of strabismus

\begin{tabular}{lcccccc}
\hline Type & \multicolumn{2}{c}{ Number of cases } & $\begin{array}{c}\text { Non } \\
\text { response }\end{array}$ & Total & $\begin{array}{c}\text { \% of total } \\
\text { amblyopia }\end{array}$ & Prevalence \\
\cline { 2 - 6 } & $\begin{array}{c}\text { With } \\
\text { amblyopia }\end{array}$ & $\begin{array}{c}\text { Without } \\
\text { amblyopia }\end{array}$ & & & & \\
\hline Esotropia & $5(22.7 \%)$ & $14(63.6 \%)$ & $3(13.6 \%)$ & $22(100 \%)$ & $62.5(5)$ & 0.067 \\
Exotropia & $3(30.0 \%)$ & $5(50.0 \%)$ & $2(20.0 \%)$ & $10(100 \%)$ & $37.5(3)$ & 0.041 \\
Total & 8 & 19 & 5 & 32 & $100.0(8)$ & 0.108 \\
\hline
\end{tabular}

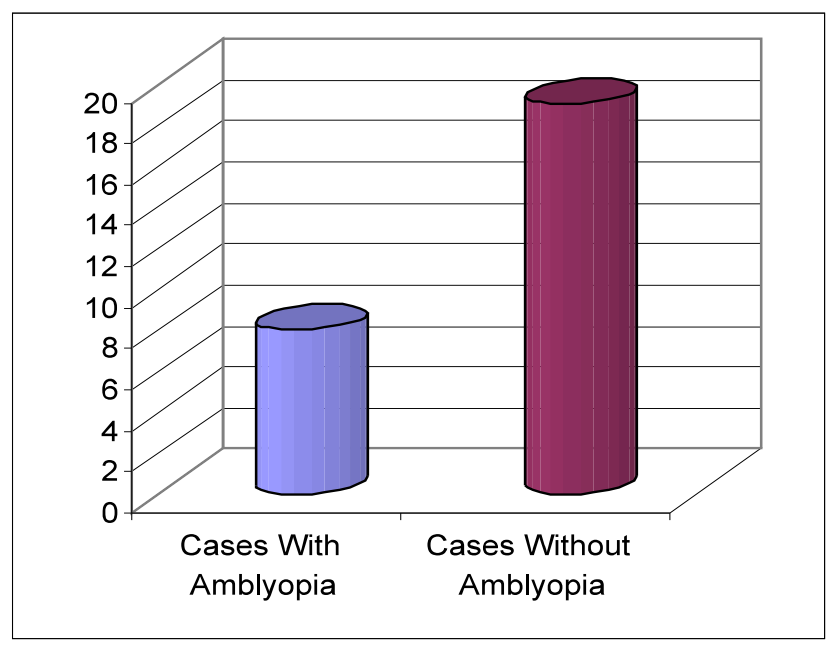

Figure 3. Distribution of amblyopia in the study population

occurred in $4.5 \%$ of the esotropic pupils. The fairly good visual status of the strabismic population may be due to the low prevalence of strabismic amblyopia in this population. Since most cases of exotropia are intermittent, this may also explain the fairly good vision observed in the exotropic population. ${ }^{6}$ Vision in the involved eye in unilateral strabismus or the nondominant eye in bilateral cases, $71 \%$ of cases had normal vision in the involved eye, while $22 \%$ had low vision in the involved eye. One child was blind, representing $7 \%$ of the involved eyes in the cases studied.

Our results are similar to the findings of $\mathrm{Abebe}^{7}$ in Ethiopia. He found that $69 \%$ of cases have normal vision in the involved eye and $20.0 \%$ have low vision in the involved eye; $11.0 \%$ of cases were blind in the involved eye.

In the 'Ilorin Study' amblyopia was found in $25 \%$ of the strabismic patients. This differs from the findings of $\mathrm{Abebe}^{7}$ in Ethiopia, where amblyopia was found in $33 \%$ of the strabismic patients. However the findings of Abeba and Abebe ${ }^{8}$ and Marrakchi et al. ${ }^{9}$ do not correspond to the Ilorin study. Amblyopia occurred in 51.7\% of cases studied by Abeba and Abebe in Ethiopia and in $58.0 \%$ of cases studied by Marrakchi et al. in Tunisia.

The results of the Ilorin study show similarities when comparing the prevalence of strabismic amblyopia $(0.11 \%)$ with studies of Matsuo and Matsuo ${ }^{10}$ in Japan and Balogun ${ }^{11}$ in Lagos, who found the prevalence of strabismic amblyopia to be $0.14 \%$ and $0.20 \%$ respectively.

These findings however, are not consistent with the findings of some other authors. ${ }^{12,13,14}$ For example, in the United States, Friedman et al. ${ }^{12}$ found a prevalence of $0.5 \%$; while in Madagascar, Auzemery et 
al. ${ }^{13}$ found a prevalence of $0.37 \%$. In the Sultanate of Oman, ${ }^{14}$ Lithander found a prevalence of $0.48 \%$.

In the Ilorin study, $62.5 \%$ of amblyopia was associated with esotropia while $37.5 \%$ was associated with exotropia. This is consistent with the findings of $\mathrm{Abebe}^{7}$ in Ethiopia where $86 \%$ of the amblyopia was associated with esotropia and $14 \%$ with exotropia. Thus esotropia is more likely to be associated with amblyopia than exotropia.

Amblyopia was found in $22.7 \%$ of cases of esotropia and $30 \%$ of cases of exotropia in this study. This is much lower than the findings of Ebana Mvogo et al. ${ }^{15}$ in Cameroon where amblyopia occurred in $68.6 \%$ of esotropia and $59.3 \%$ of exotropia.

\section{CONCLUSION}

Visual loss is the most serious consequence of strabismus and this is due mainly to amblyopia. Information on the visual pattern of strabismic children is scanty. This study is the first to look at strabismus in a population of school children in Ilorin. The majority of strabismic children had normal vision. The prevalence of strabismic amblyopia was low in the study population and most of it was associated with esotropia.

Results from other countries show a rather wide variety of strabismic eyes associated with amblyopia. More studies should be undertaken throughout Nigeria to see if any pattern emerges.

\section{REFERENCES}

1. Broderick P. Paediatric vision screening for the family physician. American Family Physician 1998; 58: 691-700.
2. Freeman AW, Nguyen VA, Jolly N. Component of visual acuity loss in strabismus. Vision Res 1996; 36: 765-774.

3. Keech RV. Practical management of amblyopia Focal points 2000; 18: 1-8.

4. Renee R, Steven G, Thomas H J. A Text and Atlas of Strabismus Surgery. $1^{\text {st }}$ ed. London: Chapman and Hall, 1991, 208-210.

5. Basic and clinical science course. Section 6: Paediatric ophthalmology and strabismus. 2001-2002: 45-52.

6. Chuka-Okosa CM. Amblyopia, types, presentation and treatment - A review. Nig J Ophthalmology 2003, 11: 54-62.

7. Abebe B. Unilateral blindness and low vision due to strabismic amblyopia. Ethiop J Health Dev 2000; 14: 109-112.

8. Abeba TG, Abebe B. Prevalence of strabismus among preschool children community in Butajira town. Ethiop J Health Dev 2001; 15: 125-130.

9. Marrakchi S, Nacef L, Hamaza B, Slim N, Ayed S, Daghfous MT. Epidemiologic study of strabismic amblyopia in Tunisia. $J$ Fr Ophthalmol 1998; 12: 819-823.

10. Matsuo T, Matsuo C. The prevalence of strabismus and amblyopia in Japanese elementary school children. Ophthalmic Epidemiol 2005; 12 : 31-36.

11. Balogun BG. Vision screening among primary school children in Mainland Local Government area of Lagos. Fellowship dissertation. National Postgraduate Medical College of Nigeria, Lagos, 1999.

12. Friedman $Z$, Neumann E, Hyams SW, Pelag B. Ophthalmic screening of 38,000 children, age $1-2 \frac{1}{2}$ years in child welfare clinics. J Peadiatr Ophthalmol Strabismus 1980; 17: 261-267.

13. Auzemery A, Andrimanamihaja R, Boisier P. Survey of prevalence and causes of eye disorders in primary school children in Antananarivo. Sante 1995; 5: 163-166.

14. Lithander J. Prevalence of amblyopia with anisometropia or strabismus among school children in the Sultanate of Oman. Acta Ophthalmol Scand 1998; 76: 658-662.

15. Ebana Mvogo C, Balle-Hiag AL, Epesse M. Strabismus in Cameroon. J Fr Ophthalmol 1996. 19: 705-9. 